\title{
Bile Duct Stenosis
}

National Cancer Institute

\section{Source}

National Cancer Institute. Bile Duct Stenosis. NCI Thesaurus. Code C78182.

Narrowing or stricture of the bile duct. 